\title{
Adverse effect of topical methylsalicylate ointment on warfarin anticoagulation: an unrecognized potential hazard
}

\author{
A.S.B. Yip, W.H. Chow, Y.T. Tai and K.L. Cheung \\ Department of Medicine, The Grantham Hospital, 125 Wong Chuk Hang Road, Aberdeen, Hong Kong.
}

\begin{abstract}
Summary: The adverse effect of topical methylsalicylate ointment on warfarin anticoagulation is studied in 11 patients. All patients had an abnormally elevated international normalized ratio after significant usage of topical methylsalicylate ointment as obvious from both the clinical history and a positive blood level of salicylate. Out of the 11 patients, 3 had bleeding manifestation; 2 with bruises and 1 with gastrointestinal bleeding. It is concluded that topical methylsalicylate ointment should be prescribed with care to patients on warfarin and excessive usage is to be avoided since potentially dangerous drug interaction could occur.
\end{abstract}

\section{Introduction}

Methylsalicylate, an active ingredient in many topical analgesic preparations, is effective for ameliorating painful musculoskeletal disorders of various aetiologies. The use of topical methylsalicylate ointment in patients with cardiac disease, however, may result in its therapeutic combination with warfarin prescribed for the purpose of thromboembolic prophylaxis. Recently, Chow and colleagues described a patient who had potentiation of warfarin anticoagulation by topical methylsalicylate ointment. ${ }^{1}$ In this paper, we report our experience in 11 patients who demonstrated adverse effects of topical methylsalicylate ointment on warfarin anticoagulation, with the possibility of potential major bleeding manifestation.

\section{Materials and methods}

Patients seen at our anticoagulation clinic who had an abnormally high international normalized ratio (INR) and a history of significant topical methylsalicylate ointment usage were admitted to the hospital for study and evaluation. Additional medications, presence of other systemic diseases, amount and duration of topical methylsalicylate ointment usage prior to admission were carefully assessed. Each patient was also asked and examined for evidence of bleeding manifestation. Complete blood counts, liver function tests and

\footnotetext{
Correspondence: W.H. Chow M.B., B.S.(HK)., M.R.C.P. (UK)

Accepted: 3 January 1990
}

blood salicylate level were measured. Tests were repeated 6 weeks later when they were seen and assessed at the anticoagulation clinic.

\section{Results}

The clinical features are listed in Table I. A total of 11 patients was studied. There were 5 men and 6 women with a mean age of 52 years (range 39 to 65). Their anticoagulation status had been stable and they were within the therapeutic range of 2 to 3 for not less than two months prior to the present admission. All were free of other systemic diseases and admitted to taking no additional medications apart from topical methylsalicylate ointment for the relief of painful musculoskeletal disorders. Eight patients obtained the ointment from their family practitioners whereas the others were from the chemist. They paid no attention to the prescription direction $(5 \mathrm{mg}$ thrice daily to the affected areas) and had been using at least 2 to $4 \mathrm{~g}$ of topical methylsalicylate ointment liberally for the last 2 weeks.

All 11 patients had an abnormally elevated INR and a positive blood level for salicylate, indicating significant percutaneous absorption of methylsalicylate had occurred. Platelet counts and liver function tests were normal. Out of the 11 patients, 3 had bleeding manifestation. Two patients presented with diffuse bruises and 1 patient had evidence of gastrointestinal bleeding. All patients were managed conservatively with fresh frozen plasma replacement and whole blood transfusion when indicated. They were told not to use the analgesic 
Table I Clinical features of 11 patients studied

\begin{tabular}{|c|c|c|c|c|c|c|c|}
\hline \multirow{3}{*}{ Patient } & \multirow{3}{*}{$\begin{array}{l}\text { Sex/Age } \\
\text { (yrs) }\end{array}$} & \multirow{3}{*}{$\begin{array}{l}\text { Indication for } \\
\text { warfarin }\end{array}$} & \multirow{3}{*}{$\begin{array}{l}\text { Indication for topical } \\
\text { methylsalicylate ointment }\end{array}$} & \multicolumn{2}{|c|}{$I N R$} & \multirow{3}{*}{$\begin{array}{l}\text { Bleeding } \\
\text { manifestations }\end{array}$} & \multirow{3}{*}{$\begin{array}{c}\text { Blood salicylate level } \\
(\mathrm{mmol} / \mathrm{l})\end{array}$} \\
\hline & & & & Before & After & & \\
\hline & & & & & & & \\
\hline 1. & $\mathrm{M} / 56$ & MVR & OA pain & 2.3 & 4.2 & Nil & 0.22 \\
\hline 2. & $\mathrm{~F} / 50$ & MVR & OA pain & 2.4 & 5.2 & Bruises & 0.50 \\
\hline 3. & $\mathrm{~F} / 39$ & MVR & Myalgia & 2.0 & 5.0 & Nil & 0.30 \\
\hline 4. & $\mathrm{M} / 64$ & MVR & $\mathrm{OA}$ pain & 2.1 & 4.35 & Nil & 0.50 \\
\hline 5. & $\mathrm{M} / 61$ & AVR & OA pain & 1.9 & 5.2 & Nil & 0.35 \\
\hline 6. & $\mathrm{~F} / 57$ & MS,AF & Myalgia & 2.6 & 4.4 & Nil & 0.60 \\
\hline 7. & $\mathrm{~F} / 58$ & MVR & OA pain & 2.2 & 4.35 & Nil & 0.40 \\
\hline 8. & $\mathrm{~F} / 41$ & MVR & Myalgia & 2.7 & 4.2 & Bruises & 0.40 \\
\hline 9. & $\mathrm{M} / 15$ & AVR & Myalgia & 2.6 & 3.76 & Nil & 0.10 \\
\hline 10. & $\mathrm{~F} / 65$ & MVR & OA pain & 2.4 & 5.5 & GIB & 0.80 \\
\hline 11. & $\mathrm{~F} / 64$ & MVR & OA pain & 2.1 & 3.3 & Nil & 0.10 \\
\hline
\end{tabular}

MVR, mitral valve replacement; AVR, aortic valve replacement; MS, mitral stenosis; AF, atrial fibrillation; OA, osteoarthritis; GIB, gastrointestinal bleeding

ointment any more. The patient with gastrointestinal bleeding was investigated with gastroscopy. No peptic ulcerations were detected. When seen at the anticoagulation clinic 6 weeks later, all patients had remained well. They were taking their usual dosage of warfarin and INR were all within the therapeutic range of 2 to 3 . Blood level for salicylate was undetectable.

\section{Discussion}

Methylsalicylate, an active ingredient in many topical analgesic preparations, has received little attention with regard to its adverse interaction with warfarin. The 11 case studies provide evidence that topical methylsalicylate ointment potentiates the anticoagulation effect of warfarin. The anticoagulation status of all patients had been stable for at least 2 months prior to admission. Platelet counts and liver function tests were normal. No patients had evidence of systemic diseases and had taken no additional medications apart from topical methylsalicylate ointment. Significant usage and percutaneous absorption of topical methylsalicylate ointment had occurred as obvious from both the clinical history and a positive blood level of salicylate. The acute rise of INR in our patients had, therefore, to be explained by drug interaction between salicylate and warfarin. Furthermore, after withdrawal of the offending drug and keeping the previous dosage of warfarin, all patients had an INR within the therapeutic range of 2 to 3 at follow-up.

Unlike phenylbutazone which has a significant effect on warfarin metabolism, ${ }^{2}$ salicylate appears to augment warfarin anticoagulation in other ways. First, in high dose, it has been reported to prolong INR in its own right by depressing prothrombin formation in the liver ${ }^{3,4}$ Second, salicylate is also known to be capable of displacing warfarin from protein binding sites. ${ }^{5}$ The mechanisms by which drugs that bind to plasma proteins and displace warfarin leading to an increase in free drug level have been described by Koch-Weser and Sellers. ${ }^{5}$ The magnitude of anticoagulation potentiation varies between individuals and might in fact be rapidly reversed by an increased clearance of warfarin due to a rise in free drug available for metabolism. ${ }^{5}$ In our patients, potentiation of warfarin anticoagulation appears unrelated to the blood salicylate level. All these actions of salicylate, together with its deleterious effects on platelets, ${ }^{6,7}$ albeit highly variable ${ }^{8,9}$ may be lethal when major bleeding manifestation happens to occur.

Topical methylsalicylate ointment, which has been used liberally and widely in all kinds of musculoskeletal disorders, should be prescribed with care to patients on warfarin and excessive usage is to be avoided since potentially dangerous drug interaction could occur. This unrecognized potential hazard certainly deserves more attention by both patients and medical personnel at the anticoagulation clinic. 


\section{References}

1. Chow, W.H., Cheung, K.L., Ling, H.M. \& See, T. Potentiation of warfarin anticoagulation by topical methylsalicylate ointment. J R Soc Med 1989, 82: 501-502.

2. O'Callaghan, J.W., Thompson, R.N. \& Russell, A.S. Combining NSAIDS with anticoagulants: yes and no. Can Med Assoc $J$ 1984, 131: 857-859.

3. Fausa, O. Salicylate-induced hypoprothrombinaemia. Acta Med Scand 1970, 188: 403-408.

4. Reynolds, J.E.F. (ed.). Martindale. The Extra Pharmacopoeia. The Pharmaceutical Press, London, 1982, p. 236.

5. Koch-Weser, J. \& Sellers, E.M. Drug interaction with coumarin antocoagulants (First of two parts). N Engl J Med 1971, 285: 487-498.
6. O'Brien, J.R. Aspirin and platelet aggregation. Lancet 1968, i: 204-205.

7. Weiss, H.J. \& Aledort, L.M. Impaired platelet/connectivetissue reaction in man after aspirin ingestion. Lancet 1967, ii: 495-497.

8. Starr, K.J. \& Petrie, J.C. Drug interactions in patients on long-term oral anticoagulant and antihypertensive adrenergic neurone-blocking drugs. $\mathrm{Br}$ Med J 1972, 4: 133-135.

9. Udall, J.A. Drug interference with warfarin therapy. Clin Med 1970, 77: $20-25$. 